Check for updates

Cite this: J. Mater. Chem. A, 2021, 9, 19854

Received 31st March 2021

Accepted 26th May 2021

DOI: $10.1039 / \mathrm{d} 1 \mathrm{ta0} 2664 \mathrm{j}$

rsc.li/materials-a

\section{Post-transition metal/polymer composites for the separation and sensing of alkali metal ions $\dagger$}

\author{
Salma Merhebi, ${ }^{a}$ Munirah Mohammad, ${ }^{a}$ Mohannad Mayyas, (D) ${ }^{a}$ Roozbeh Abbasi, ${ }^{a}$ \\ Chengchen Zhang, ${ }^{a}$ Shengxiang Cai, ${ }^{a}$ Franco Centurion, (D) ${ }^{a}$ Wanjie Xie, ${ }^{a}$ \\ Zhenbang Cao, ${ }^{a}$ Junma Tang, ${ }^{a}$ Md Arifur Rahim, ${ }^{a}$ Jin Zhang, ${ }^{b}$ Amir Razmjou, (D) ac \\ Greg Leslie, ${ }^{a}$ Kourosh Kalantar-Zadeh, (D) *a Jianbo Tang (D) *a \\ and Francois-Marie Allioux ${ }^{\star a}$
}

The separation and sensing of alkali metal ions from aqueous lithium resources is of great importance for building future renewable and lithium-based energy storage technologies. As such, interest arises for the development of functional composites selective to ionic lithium $\left(\mathrm{Li}^{+}\right)$over sodium $\left(\mathrm{Na}^{+}\right)$and potassium $\left(\mathrm{K}^{+}\right)$that allows for a range of low carbon-footprint sensing and recovery processes. Here, selective separation of $\mathrm{Li}^{+}$from aqueous mixtures of $\mathrm{Na}^{+}$and $\mathrm{K}^{+}$ions using polyvinyl alcohol/maleic acid composites was enhanced by the inclusion as nano-additives of post-transition metals gallium (Ga) and indium (In), together with their alloys and oxidized species, in the composite casting process. The coaddition of $\mathrm{Ga}$ and In resulted in the spontaneous formation of $\mathrm{Ga}$ oxides and hydroxides while In remained in the metallic state. This Ga-In composite was stable in aqueous solutions containing a high concentration $(0.1 \mathrm{M})$ of mixed alkali metal ions over 5 days and achieved exceptionally high selectivities of $\mathrm{Li}^{+}$over $\mathrm{Na}^{+}(3.8 \pm 0.1)$ and $\mathrm{K}^{+}(7.1 \pm 0.1)$. Results from an electrochemical sensing platform technique revealed that $\mathrm{Li}^{+}$selectivity was in the same order as the diffusion rates. This work demonstrated that the low-melting-point post-transition metal alloy enables a one-step low energy fabrication of selective polymeric composites with diverse applications for energy, sensing and separation industries. The work has implications for the efficient manufacture of renewable and lithiumbased energy storage technologies.

\section{Introduction}

Post-transition metals are a class of materials considered as metalloids with low melting points that exhibit peculiar properties such as mixed metallic and covalent bonding within their structures. ${ }^{1,2}$ Particularly, gallium (Ga) and indium (In), and their oxides, show unique lithiation properties. ${ }^{3-5}$ For instance, one atom of Ga can host two atoms of lithium (Li). ${ }^{6}$ Bulk Ga forms an eutectic alloy with lithium at a reported temperature as low as $27.5 \pm 2{ }^{\circ} \mathrm{C}$ for 1.7 at\% (atomic percentage) $\mathrm{Li}^{7}$ Similarly, In forms a wide range of intermetallic compounds with $\mathrm{Li}$ and presents a high lithium ion $\left(\mathrm{Li}^{+}\right)$diffusion coefficient within its semi-metallic matrix. ${ }^{8}$ As such, both Ga and In-

${ }^{a}$ School of Chemical Engineering, University of New South Wales (UNSW), Sydney, New South Wales, 2052, Australia.E-mail: k.kalantar-zadeh@unsw.edu.au; jianbo.tang@ unsw.edu.au; f.allioux@unsw.edu.au

${ }^{b}$ School of Mechanical and Manufacturing Engineering, UNSW, Sydney, New South Wales, 2052, Australia

${ }^{c}$ Centre for Technology in Water and Wastewater, University of Technology Sydney, New South Wales, Australia

$\dagger$ Electronic supplementary information (ESI) available. See DOI: $10.1039 / \mathrm{d} 1 \mathrm{ta0} 0266 \mathrm{j}$ based metals, alloys and oxides present high affinity to Li ionic species and compounds and are outstanding candidates to explore new Li recovery pathways. In addition, due to their lowmelting points, pure $\mathrm{Ga}$, In and their alloys can be processed into nanoparticles decorated by surface oxide nanostructures. ${ }^{9-13}$ These nanostructured additives can be included into various polymeric matrices to form composites presenting attractive properties for ions sensing and selective ions recovery such as $\mathrm{Li}^{+}$.

The recovery of $\mathrm{Li}^{+}$with low environmental impact and carbon-footprint is necessary for the development of sustainable energy systems that combine renewable and battery storage. $^{\mathbf{1 4 , 1 5}}$ The global lithium demand for battery manufacturing is expected to double by 2030 as the transition to intelligent energy systems occurs. ${ }^{15,16}$ Conventional hard rock $\mathrm{Li}$ mining and high-temperature refining operations negatively impact the carbon emission reduction strategy of battery energy storage applications. ${ }^{15,17}$ In contrast, the extraction of $\mathrm{Li}^{+}$from brines is considered to have up to $50 \%$ lower carbon footprint. However, the extraction of $\mathrm{Li}^{+}$, from these unconventional resources including continental, oil fields or geothermal brines, 
seawater, and waste streams, is currently impaired by the lack of selective and stable separation materials. ${ }^{17,18}$

In classical ionic separation processes, the efficient recovery of $\mathrm{Li}^{+}$is limited by the difficulty in separating $\mathrm{Li}^{+}$from other alkali metal ions. ${ }^{\mathbf{1 8 - 2 0}}$ Ionic sodium $\left(\mathrm{Na}^{+}\right)$and potassium $\left(\mathrm{K}^{+}\right)$ exhibit similar chemical properties including the same valence and close ionic radii for physical separation. ${ }^{\mathbf{1 8 2 1}}$ The reversible ionic selectivity of a material is reported to arise from the energy of interactions between hydrated ions and functional binding sites. ${ }^{18,22}$ A number of materials have been proposed for the selective separation of $\mathrm{Li}^{+}$in aqueous media but the development of materials with high selectivity, reversibility and stability remains challenging at scale. ${ }^{\mathbf{1 8 2 2 , 2 3}}$

Functional materials are often deposited at the surface of a polymeric support as a selective layer or embedded into a polymeric matrix as selective additives..$^{\mathbf{9} 24-28}$ The polymeric material provides additional mechanical support to the fillers, which can either be inert or play an active role such as facilitating the diffusion of ionic species. ${ }^{\mathbf{2 9 , 3 0}}$ For the separation of alkali metal ions and the recovery of $\mathrm{Li}^{+}$mixed in solution with $\mathrm{Na}^{+}$and $\mathrm{K}^{+}$, the base polymeric matrix should allow the passage of $\mathrm{Na}^{+}$and $\mathrm{K}^{+}$, exhibit negatively charged functional groups and possess a relatively high hydrophilicity.

Here we choose polyvinyl alcohol (PVA) as a hydrophilic, semicrystalline polymer that presents a charged matrix with functional hydroxyl and carbonyl groups providing high conductivity and permeability to both $\mathrm{Na}^{+}$and $\mathrm{K}^{+} \cdot{ }^{31-33}$ Strong interactions between the functional groups of PVA and $\mathrm{Li}^{+}$were also previously reported but were shown to induce intermolecular charge transfer leading to detrimental changes in the physicochemical stability of PVA. ${ }^{31}$ Cross-linking or direct coordination with the selective additives are ways to mitigate the weakening of the PVA matrix..$^{32,34} \mathrm{Ga}$, In and Ga-In alloys have also recently been demonstrated to be stabilized by the charged PVA matrix resulting in conductive ionic junctions between the charged groups and the metallic species. ${ }^{9}$ Considering the interactions of $\mathrm{Li}^{+}$with PVA, Ga, In and their alloys, we investigate the possibility to use a composite of these materials for the selective sensing and separation of $\mathrm{Li}^{+}$from $\mathrm{Na}^{+}$and $\mathrm{K}^{+}$in aqueous media.

In this work, Ga, In and Ga-In alloys were dispersed into a PVA solution before casting and cross-linking reaction to form thin flat-sheet composites. The low melting point of these posttransition metals and alloys allowed the preparation of the dope solutions in benign solvents and at low temperatures. The physicochemical characteristics together with the sensing and selectivity $\mathrm{Li}^{+}$over $\mathrm{Na}^{+}$and $\mathrm{K}^{+}$were measured for the composites containing mixed metallic and oxide compounds. Insights on the structure and performance of the composites were used as the basis for a proposed selectivity mechanism based on hindered diffusion in aqueous solutions.

\section{Experimental}

\section{Materials}

In (beads, 99.9\% purity) and Ga (beads, 99\%) were purchased from Rotometals, USA. Lithium chloride (LiCl, $\geq 99 \%$ ), sodium chloride $(\mathrm{NaCl}, \geq 99 \%)$ and potassium chloride $(\mathrm{KCl}, \geq 99 \%)$ were obtained from Chem-Supply Pty Ltd., Australia. PVA $\left(M_{\mathrm{w}}=\right.$ 85 000-124000 $\mathrm{g} \mathrm{mol}^{-1}$, 99+\% hydrolyzed) and maleic acid (MA, $\geq 99 \%$ ) were procured from Sigma-Aldrich, Australia. All materials were used as received without further purification. Eutectic Ga-In (EGaIn) alloy was obtained by melting together $74.5 \mathrm{wt} \% \mathrm{Ga}$ and $25.5 \mathrm{wt} \%$ In at $80{ }^{\circ} \mathrm{C}$ for $1 \mathrm{~h}$.

\section{Dope preparation and composite synthesis}

$\mathrm{Ga}$, In and EGaIn were used for the formation of nano-additives in the PVA/MA base matrix. First, a $10 \mathrm{wt} \%$ PVA solution was prepared by dissolving PVA powder into deionized (DI) water under mechanical stirring at $80{ }^{\circ} \mathrm{C}$ for $2 \mathrm{~h}$. Then, MA $(40 \% \mathrm{w} / \mathrm{w}$ with respect to the weight of PVA) was mixed with the solution under constant stirring for another $2 \mathrm{~h}$. Ga and EGaIn composites were prepared by directly adding the metal or alloy into the PVA/MA dope solution (1: 1 weight ratio), followed by sonication using a probe sonicator (VCX 750, Sonics \& Materials, Inc.). The sonication was performed in a water bath to mitigate the temperature rise during the process. The power intensity of the sonicator was kept at $40 \%$ of its maximum power $(750 \mathrm{~W})$ for a duration set between 10 to $40 \mathrm{~min}$. The In nano-additives were first prepared by melting the In beads in glycerol on a hotplate above the In melting point $\left(>156.6^{\circ} \mathrm{C}\right)$ and then sonicated under the same power and time duration as for the preparation of $\mathrm{Ga}$ and EGaIn dope solutions. The asprepared In nano-additives were centrifuged and washed thoroughly before mixing with the PVA/MA solution (1:1 weight ratio) on a roller mixer overnight.

The dope solutions containing the nano-additives were then cast according to a wet thin film fabrication technique using a casting knife (TQC Sheen) at a traverse speed of $1 \mathrm{~mm} \mathrm{~s}^{-1}$. The gap between the clear float glass plate and the casting blade was adjusted to control the film thickness. The films were dried at ambient temperature overnight and subsequently cured in an oven at $140{ }^{\circ} \mathrm{C}$ for $90 \mathrm{~min}$ to cross-link the PVA/MA polymer matrix. The as-formed composites were gently peeled from the glass plate in a coagulation bath.

\section{Characterizations}

Surface wettability of the composites with different nanoadditives was expressed as the average of triplicate measurements of water contact angle for each sample (KSV Cam 200). Mechanical properties were measured in triplicate on rectangular samples (length $\times$ width $\times$ thickness: $30 \mathrm{~mm} \times 15 \mathrm{~mm} \times$ $20 \mu \mathrm{m}$ ) at a loading rate of $100 \mathrm{~mm} \mathrm{~min}^{-1}$ on an Instron 3369 universal mechanical tester (Instron, UK).

The glass transition temperature $\left(T_{\mathrm{G}}\right)$ of the composites was determined by differential scanning calorimetry (DSC) measurements (Q20, TA Instruments) with temperatures ranging from 25 to $150{ }^{\circ} \mathrm{C}$ at $10{ }^{\circ} \mathrm{C} \mathrm{min}{ }^{-1}$ heating and cooling rates. The electrical resistances of the composites were measured using a two-probe method with a digital multimeter (model Siglent SDM3065X).

The morphologies and elemental distributions of the nanoadditives within the PVA/MA matrix were characterized by 
scanning electron microscopy (SEM, JEOL InTouchScope, JSMIT500HR) and energy-dispersive X-ray spectroscopy (EDS, JEOL, Ex-74600U4L2Q model). The size distributions of the nano-additives were determined from the SEM images using the Image Software Package (1.52a). The average roughnesses $\left(R_{\mathrm{a}}\right)$ of the composites were determined from profilometer measurements using a KLA Tencor D-600 Stylus Profiler instrument.

The vibrational properties of the composites were characterized by Fourier transform infrared spectroscopy (FTIR, PerkinElmer spectrometer) and Raman spectroscopy (inVia Raman microscope, RENISHAW, $532 \mathrm{~nm}$ laser source, laser power 5\%, exposure time $10 \mathrm{~s}$ ). The X-ray diffraction (XRD) patterns were obtained using a X'pert multipurpose X-ray diffraction system (PANalytical, $\lambda=1.54 \AA$, $\mathrm{Cu} \mathrm{K} \alpha$ radiation). Surface chemical compositions were characterized by X-ray photoelectron spectroscopy (XPS, Thermo Scientific ESCALAB 250 Xi, monochromated $\mathrm{Al} \mathrm{K} \alpha$ ) with a photon and pass energy of 1486.7 and $50 \mathrm{eV}$, respectively. The XPS data were analyzed with the Advantage software and a calibration using the $\mathrm{C}$ 1s peak at $284.8 \mathrm{eV}$.

Sensor devices were fabricated by drop-casting the dope solutions onto silver-palladium (Ag-Pd) electrodes. These electrode composites were then cross-linked following the same procedure as previously described. The electrochemical sensing experiments were performed on an electrochemical station (CHI650E).

Ionic diffusion tests were performed in a diffusion cell with $\mathrm{LiCl}, \mathrm{KCl}, \mathrm{NaCl}$ or their mixtures in one compartment of the cell (feed) and DI water on the other compartment (permeate). The conductivity in the compartments was measured using a conductivity meter (HI 8733 model). The elemental concentration in the solutions was measured using inductively coupled plasma optical emission spectroscopy (ICP-OES, Avio 500DV). Electro-diffusion experiments were also performed using the diffusion cell. A DC voltage was applied across the two compartments using platinum (Pt) electrodes placed in the feed and the permeate compartments. A DC voltage was also directly applied to the material either in series with one of the electrodes or as a stand-alone electrode.

Zeta potentials were determined using the Zeta Potential Analyzer (SurPASS, Anton Paar). Two $2 \mathrm{~cm} \times 1 \mathrm{~cm}$ samples were mounted facing each other to form a capillary of $100 \mu \mathrm{m}$ width; in which a measuring electrolyte of $0.001 \mathrm{M} \mathrm{KCl}$ was streamed through until reaching equilibrium. Potassium hydroxide $(\mathrm{KOH}, 0.1 \mathrm{M})$ was used for basic titration from $\mathrm{pH} 5$ to 8. The streaming potential measurement was used to calculate surface zeta potential using Attract 2.0 software.

The composites fabrication, characterization, and testing were performed in a controlled laboratory environment of $21^{\circ} \mathrm{C}$ average room temperature and 50\% relative humidity.

\section{Results and discussion}

\section{Composite properties}

The composites used in this study have a charged and permeable polymetric PVA/MA matrix and post-transition metal nano- additives as selective fillers and were prepared as illustrated in Fig. 1a. The dope solutions were cast at different thicknesses, cured, and separated from the casting substrate in a coagulation bath to form the composites. The resulting composites fabricated with EGaIn nano-additives (named Ga-In composite thereafter) before and after coagulation bath are shown in the pictures in Fig. 1b and c. The typical Ga-In composites used for later experiments were $20 \mu \mathrm{m}$ thick, mechanically strong, and flexible.

The EGaIn nano-additives presented spherical morphologies with a size distribution of $0.5 \pm 0.2 \mu \mathrm{m}$ after $30 \mathrm{~min}$ of sonication (Fig. 2a). The effect of the sonication duration on the EGaIn nano-additives is reported in Fig. S1. $\uparrow$ The average size of the EGaIn nano-additives was shown to decrease with the sonication time with no noticeable size reduction after $30 \mathrm{~min}$ of sonication. EGaIn alloy was chosen due to its low melting point $\left(\sim 15.7^{\circ} \mathrm{C}\right)$ that allows the formation of nano-additives in mild conditions using low-energy agitation methods compatible with a PVA-based polymeric matrix. Similarly, the asprepared post-transition metals $\mathrm{Ga}$ and In nano-additives showed narrow size distributions as expected for such preparation procedure (Fig. S2, ESI $\dagger$ )..$^{\mathbf{9} 35-38}$ As shown with the Ga-In composite surface in Fig. 2b, uniform composites with densely packed nano-additives were fabricated. The Ga-In composite showed a rough and textured surface with an average roughness of $0.66 \mu \mathrm{m}$, which could provide an advantage for ionic separation and sensing due to the increased exchange surface area as opposed to particulate separation. ${ }^{39,40}$ Similar composite morphologies were observed for the pure Ga and In composites as seen in Fig. S3 and S4, $\dagger$ respectively. The EDS elemental mapping of the sample surface (Fig. 2c) and the cross-section (Fig. 2d) showed separated Ga and In domains across the GaIn composite, which was attributed to phase separation of the EGaIn particles during sonication. ${ }^{41}$ Furthermore, a strong oxidation of the Ga-rich phases was also observed from the oxygen elemental mapping matching the Ga elemental distribution. Similarly, the Ga particles across the Ga-composite were strongly oxidized and presented a crystalline shape representative of Ga oxide species as seen in Fig. S3. $\uparrow$ Conversely, the pure In composite showed a distribution of round-shaped In particles that retained the initial shape of the nano-additives (Fig. S2b and $\mathrm{S} 4 \dagger$ ). It can also be inferred from the crosssection views that the nano-additives were dispersed uniformly across the thickness direction for all three $\mathrm{Ga}$, In and Ga-In composites.

The surface wettability (hydrophilicity and hydrophobicity) of the composites, which were characterized by water contact angle, gives indication of the surface energy of the composites. ${ }^{\mathbf{4 2}}$ The contact angle of the composite containing Ga nanoadditives was lower as compared to the virgin PVA/MA indicating increased hydrophilicity, while in contrast the inclusion of In nano-additives increased the contact angle and produced a more hydrophobic composite (Fig. 2e). The trade-off between the influence of $\mathrm{Ga}$ and In resulted in an intermediate contact angle for the Ga-In composite. The change in contact angle was attributed to presence of the Ga oxide species. ${ }^{41}$ 
(a)

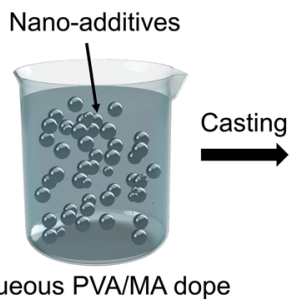

$20 \mu \mathrm{m} \sim 200 \mu \mathrm{m}$ thickness

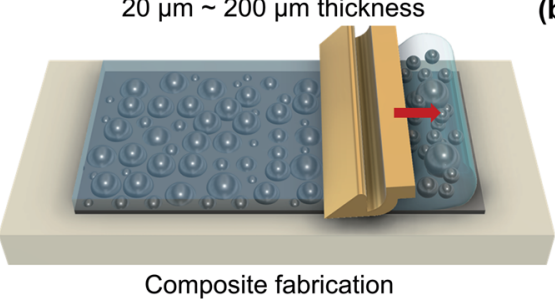

(b)

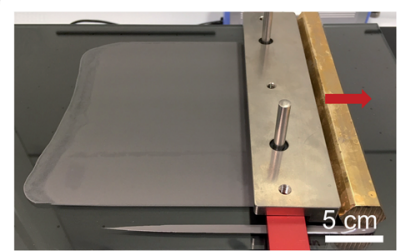

(c)

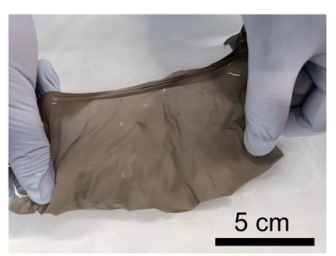

Fig. 1 (a) Schematic illustration of the composite fabrication process. Photos of the Ga-In composites (b) before and (c) after peeling.

Tensile tests showed that the addition of the nano-additives into the PVA/MA matrix significantly affected both the ultimate tensile strength and Young's modulus $(E)$ of the composites as shown in Fig. 2f. Again, the Ga-In composite showed an intermediate $E(0.029 \mathrm{MPa})$ and breaking strain in comparison to the $\mathrm{Ga}(E=0.016 \mathrm{MPa})$ and In composites (0.096 MPa). Interestingly, the degree of oxidation of the nano-additives was related to the mechanical properties of the composites. Adding Ga and Ga-In nano-additives to PVA/MA was found to reduce the $E$ since the additives introduced highly oxidized post-transition metal nano-fillers. The higher $E$ of the Ga-In composite as compared to the pure Ga composite can be understood by considering the inclusion of solid In nano-additives due to phase separation (Fig. 2c and d). By contrast, adding only solid In nano-additives showed a dramatic increase of the ultimate tensile strength of the composite as well as a slight increase of $E$.

DSC was used to measure the glass transition temperature $T_{\mathrm{G}}$ of the composites. The $T_{\mathrm{G}}$ of all three composites was increased as a result of the nano-additive inclusion as compared to PVA/MA polymer, indicating increased domains of crystallinity across the polymer phase of the composites (Fig. $2 \mathrm{~g}-\mathrm{j}$ ). ${ }^{\mathbf{4 3}}$

\section{(a)}

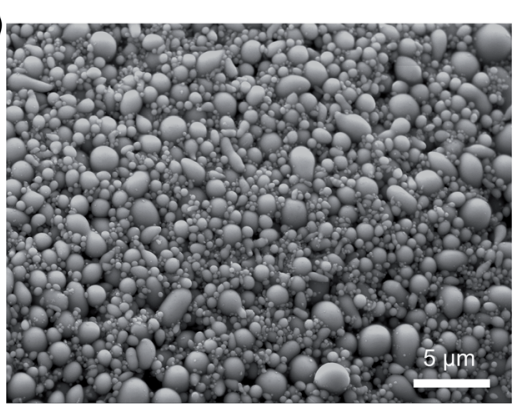

(c)
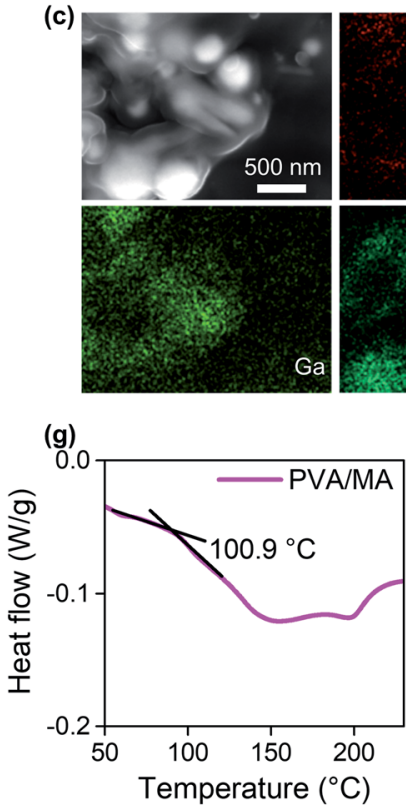

(b)
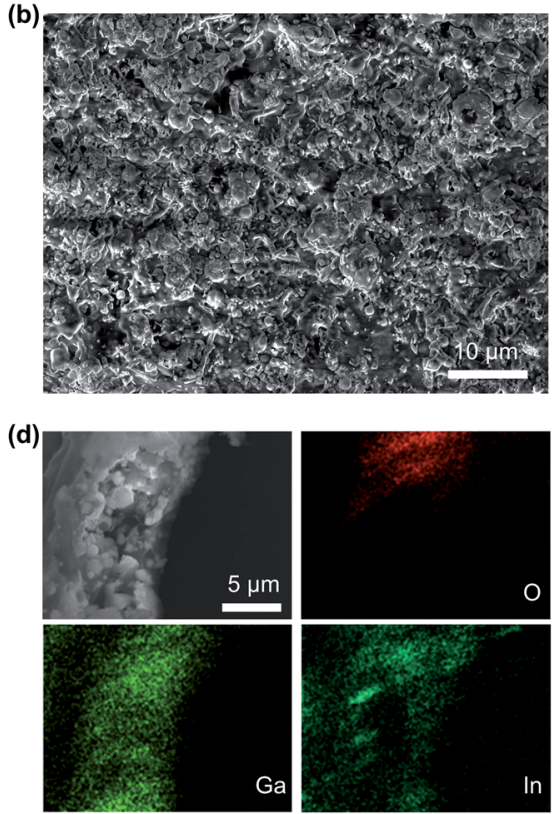

(i)

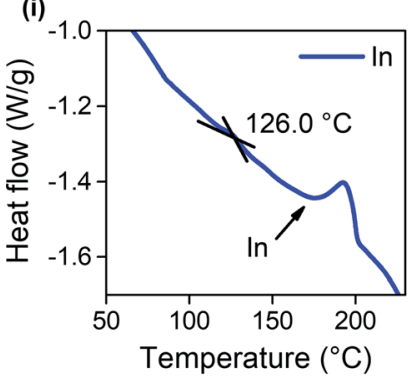

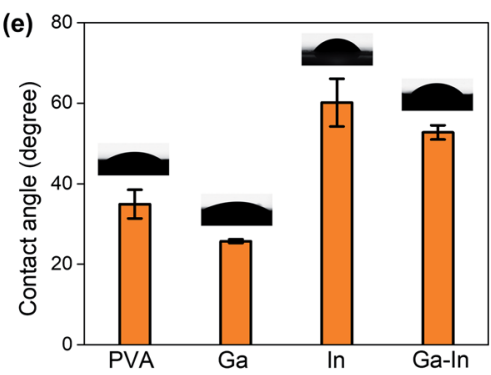

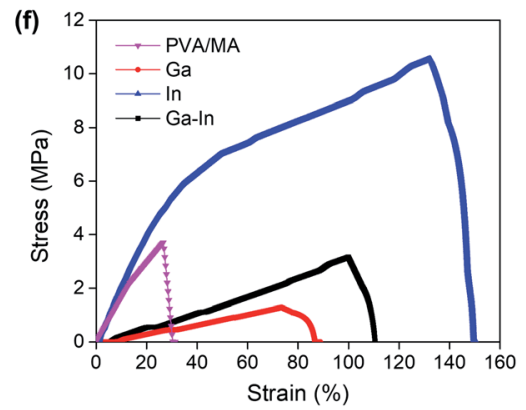

(j)
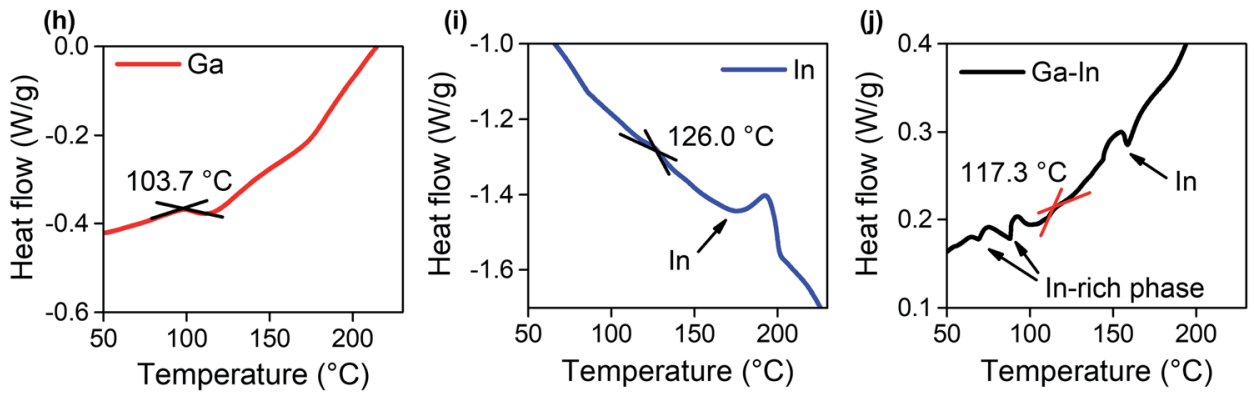

Fig. 2 (a) SEM image of the EGaln nano-additives. (b) SEM image of the surface of the Ga-In composite. EDS mapping of (c) the surface and (d) the cross-section of the Ga-In composite. (e) Water contact angle measurements at the surface of the composites. (f) Stress-strain curves of the composites. DSC analysis of the (g) PVA/MA, (h) Ga, (i) In and, (j) Ga-In composites. 
Among the three types of nano-additives, the Ga composite showed the slightest increase from $100.9^{\circ} \mathrm{C}$ (PVA/MA, Fig. 2g) to 103.7 ${ }^{\circ} \mathrm{C}$ (Fig. 2h) while the In composite had the largest increase to $126.0^{\circ} \mathrm{C}$ (Fig. 2i), with the $T_{\mathrm{G}}$ of the Ga-In composite (117.3 ${ }^{\circ} \mathrm{C}$, Fig. $2 \mathrm{j}$ ) setting between the two. When In was involved (both In and Ga-In composites), sharp peaks around $156.6{ }^{\circ} \mathrm{C}$ (In melting point) was observed from the DSC curves, which were attributed to the melting of the In or In-rich (for the Ga-In composite) nano-additives, given that glass transition usually exhibits as a smooth transition..$^{35,43}$

These results suggested that the presence of different posttransition metal, alloy, and oxide nano-additives to PVA/MA effectively modified the surface wettability, mechanical and thermal properties of the polymer matrix. The underlying mechanisms will be discussed later with the support of further material characterizations.

XRD analysis of the composites revealed that in the $\mathrm{Ga}$ composite, the Ga metal was eventually fully oxidized to form $\mathrm{Ga}_{2} \mathrm{O}_{3}$ and its hydrate form $\mathrm{GaOOH}$ (Fig. 3a). By comparison, In was largely preserved in the metallic state. The Ga-In composite also showed the existence of metallic In and the absence of metallic Ga. Comparing the XRD patterns of the composites with the PVA/MA polymer, the right-side shoulder of the characteristic PVA/MA twin peaks $\left(2 \theta \approx 43^{\circ}\right)$ became insignificant (this region may also include contributions when $\mathrm{Ga}_{2} \mathrm{O}_{3}$ exists), indicating the alteration of the crystallinity of the PVA/MA in the composites. $^{43}$ The intensity of the composites at $2 \theta \approx 51^{\circ}$, which was exclusively contributed by PVA/MA, showed a noticeable increasing trend in the order $\mathrm{Ga}, \mathrm{Ga}-\mathrm{In}$, and In. In this regard, the XRD results confirmed our discussion about the crystallinity change of the composites based on the DSC tests.
As demonstrated in Fig. 3b, FTIR revealed the decreased absorbance of the composites from the $\mathrm{C}=\mathrm{O}$ and $\mathrm{C}=\mathrm{C}$ (1707 $\mathrm{cm}^{-1}$ and $1570 \mathrm{~cm}^{-1}$, respectively), suggesting the reorganization of the PVA/MA polymeric network with the breakdown of the cross-linked chains., ${ }^{\mathbf{9 , 4}, 44}$ This was thought to be primarily responsible for the increased stretchability of the composites observed in the tensile tests (Fig. 2f). Increased absorbance occurred in the composites at near $500 \mathrm{~cm}^{-1}$ (denoted as $\mathrm{Me}-\mathrm{O}$ ), which corresponded to the coordination of the $\mathrm{Ga}$ and/or In with the oxygen functional groups in the polymer. The two In-containing (In and Ga-In) composites showed enhanced absorbance of $-\mathrm{CH}_{2}-$ and $\mathrm{CH}$ while the $\mathrm{Ga}$ composite experienced a decrease in the corresponding regions. Since the $-\mathrm{CH}_{2}$ - and $\mathrm{CH}$ are representative of the PVA/MA polymeric network, we expected the oxidized Ga species $\left(\mathrm{Ga}_{2} \mathrm{O}_{3}\right.$ and $\left.\mathrm{GaOOH}\right)$ in the composites to cause a shortening of the PVA chains, while metallic In largely preserved the PVA structure without the same shortening effect.

The FTIR results were well matched by Raman spectroscopy as seen in Fig. 3c. The intensity of the band corresponding to $\mathrm{C}=\mathrm{O}\left(1090 \mathrm{~cm}^{-1}\right)$ decreased with the addition of the nanoadditives and, that of the $-\mathrm{CH}_{2}-\left(1438 \mathrm{~cm}^{-1}\right)$ and $\mathrm{CH}$ $\left(2912 \mathrm{~cm}^{-1}\right)$ bands increased with metallic In, while decreased with Ga oxide species..$^{\mathbf{9}, \mathbf{4 3}, \mathbf{4 4}}$

XPS showed a decreasing trend of the $\mathrm{C}-\mathrm{C}$ peak intensity in the $\mathrm{C}$ 1s region $(284.8 \mathrm{eV}$ ) in the sample order PVA/MA, In, GaIn, and Ga composites (Fig. 3d). ${ }^{44}$ Meanwhile, an increasing of the $\mathrm{C}-\mathrm{O}$ peak intensity in the sample order PVA/MA, Ga, Ga-In also appeared. The enhanced $\mathrm{C}-\mathrm{O}$ peak intensity was also shown in the $\mathrm{O} 1 \mathrm{~s}$ region (Fig. 3e), where the $\mathrm{O}$ 1s peak of the PVA/MA was shifted to higher binding energy (from $\sim 531.8 \mathrm{eV}$
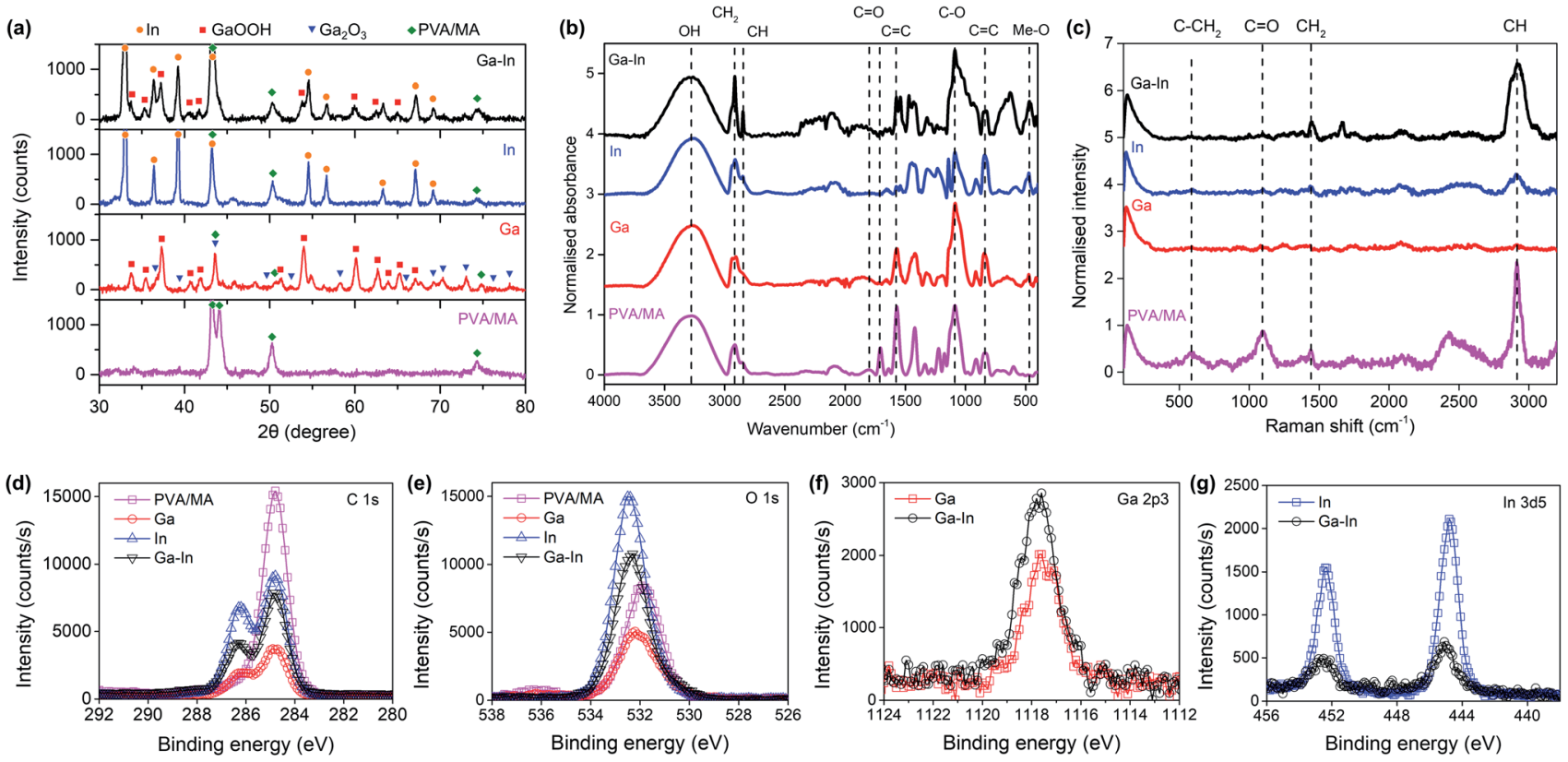

Fig. 3 (a) XRD patterns of the composites and their analysis. (b) FTIR spectra and (c) Raman spectra of the composites and their analysis. (d) Highresolution C 1s XPS spectra of the composites, and (e) high-resolution O 1s XPS spectra. (f) High-resolution Ga 2p3 XPS spectra of the Ga and GaIn composites. (g) High-resolution In 3d5 XPS spectra of the In and Ga-In composites. 
to over $532.0 \mathrm{eV}$ ) in all three composite samples, indicating increasing contribution of the $\mathrm{C}-\mathrm{O}$ bonding. The results confirmed again that the breaking the polymer matrix and the resulting formation of the $\mathrm{C}-\mathrm{O}$ bonding due to its coordination with the partially oxidized nano-additives. The Ga $2 \mathrm{p} 3$ and In $3 \mathrm{~d} 5$ regions are shown in Fig. $3 \mathrm{f}$ and $\mathrm{g}$, respectively, and XPS spectra deconvolutions are presented in Fig. S5 and S6.†

The preferential oxidation of the Ga over In nano-additives can be explained by the favorable Gibbs free energy of $\mathrm{Ga}$ oxide formation over In oxide, and was also previously reported to take place in EGaIn alloy. ${ }^{12,35,45}$

\section{Applications}

The developed composites presented sufficient mechanical stabilities, desirable textured hydrophilic surfaces, negatively charged functional chemical groups and incorporated the posttransition metal nano-additives in metallic form (In) or/and oxide and hydroxide species (Ga). Based on our initial hypothesis, we then investigated the composite materials for sensing and separation of $\mathrm{Li}^{+}$from $\mathrm{Na}^{+}$and $\mathrm{K}^{+}$in aqueous solution.

Electrochemical sensing. The diffusion and sensing of alkali metal ions $\left(\mathrm{Li}^{+}, \mathrm{K}^{+}\right.$, and $\left.\mathrm{Na}^{+}\right)$across the composites were assessed electrochemically by linear sweep voltammetry (LSV) analysis. Prior to the LSV measurements, an anodic potential of $1.0 \mathrm{~V} v s$. SCE was applied to the composites to repel cations that may have been introduced within the samples during synthesis. The LSV curves were collected in the potential window of 0 to $-0.30 \mathrm{~V} v s$. SCE. In Fig. $4 \mathrm{a}$, the LSV curves suggest that the pure PVA/MA is permeable to the three alkali metal ions. $\mathrm{K}^{+}$and $\mathrm{Na}^{+}$ show higher ionic diffusion compared to $\mathrm{Li}^{+}$. For the $\mathrm{Ga}$ composite, the $\mathrm{Na}^{+}$and $\mathrm{Li}^{+}$diffusion dropped dramatically as compared to $\mathrm{K}^{+}$as seen in Fig. $4 \mathrm{~b}$. The positive current observed in the LSV curve of the In composite for $\mathrm{Li}^{+}$was attributed to the possible corrosion of In (Fig. 4c). ${ }^{5,46}$ However, from the slope of the curve, it can be concluded that there also exists $\mathrm{Li}^{+}$diffusion through this composite. The $\mathrm{Na}^{+}$and $\mathrm{K}^{+}$also diffuse through this composite without signs of corrosion, as suggested by their LSV curves. As observed from the LSV curves of Ga-In composite (Fig. 4d), the three alkali metal ions diffused through the composite with $\mathrm{Li}^{+}$featuring the lowest diffusion. The selectivity of the Ga-In composite was estimated from the fitting of the linear region of the LSV curves (Fig. 4d) and showed a higher intensity-response for $\mathrm{K}^{+}, \mathrm{Na}^{+}$and $\mathrm{Li}^{+}$, respectively. The fittings of the LSV curves are reported in Fig. S7a. $\dagger$ In addition, no corrosion phenomena were observed for this composite suggesting the presence of a stable interface when Ga oxides or hydroxides are found in the composite, preventing chemical interactions between In and the surrounding solutions.

The LSV curves of the Ga-In composite in simulated continental brine, seawater and tertiary equimolar $(0.1 \mathrm{M}) \mathrm{Li}^{+}, \mathrm{Na}^{+}$ and $\mathrm{K}^{+}$mixtures are presented in Fig. 4e and showed an intensity-response following the relative ionic strength of the solutions. Compositions of the simulated solutions are reported in Table S1. $\dot{\dagger}^{47}$ The LSV curves of the Ga-In composite in $\mathrm{Li}^{+}$ solutions with concentrations ranging from 0.05 and $100 \mathrm{mM}$ were also assessed and presented in Fig. 4f. The minimum
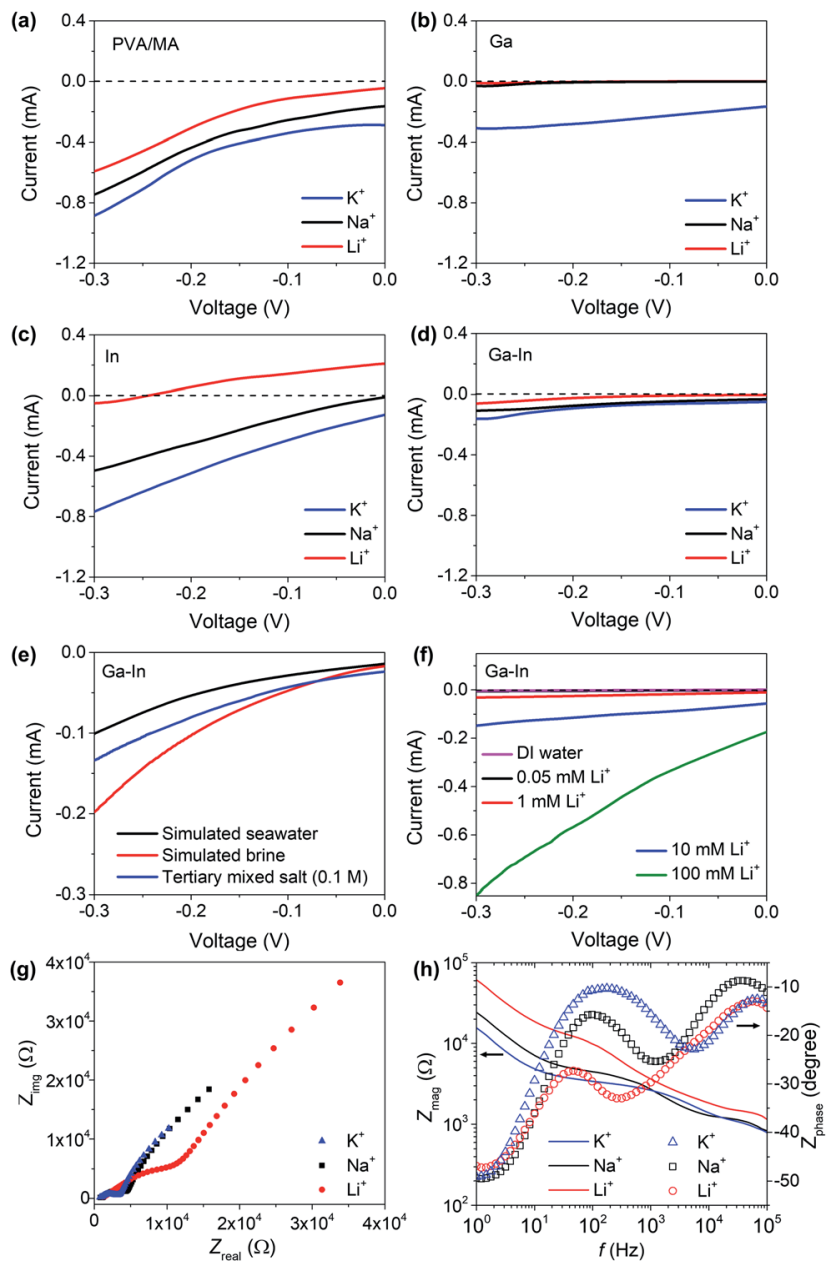

Fig. 4 (a) LSV analysis of plain PVA/MA composite, (b) Ga composite, (c) In composite and (d) $\mathrm{Ga}$-In composite in $\mathrm{Li}^{+}, \mathrm{Na}^{+}$and $\mathrm{K}^{+}$electrolytes. (e) LSV analysis of the Ga-In composite in simulated seawater, brine and tertiary solutions. (f) LSV analysis of the Ga-In composite in $\mathrm{Li}^{+}$electrolytes. (g) EIS analysis and (h) Bode plots of the $\mathrm{Ga}-\mathrm{In}$ composite in $\mathrm{Li}^{+}, \mathrm{Na}^{+}$and $\mathrm{K}^{+}$electrolytes.

detection limit for $\mathrm{Li}^{+}$was determined as $0.05 \mathrm{mM}$. The $\mathrm{Ga}-\mathrm{In}$ composite showed a linear response in the range of 0.05 to $100 \mathrm{mM}$ as presented in Fig. S7b. $\dagger$ The effect of the $\mathrm{pH}$ on the ionic diffusion trough the Ga-In composite was studied from $\mathrm{pH}=5$ to $\mathrm{pH}=8.5$, which corresponded to the reported range of $\mathrm{pH}$ values for brines and seawater, respectively. The LSV curves of the Ga-In composite in the tertiary mixed salt solutions showed a limited effect of the $\mathrm{pH}$ at 7 and 8.5 (Fig. S7c $\dagger$ ). However, in more acidic conditions ( $\mathrm{pH}=5)$, the ionic diffusion was reduced, which can be attributed to the lower ionization state of the PVA matrix. ${ }^{32}$ The effect of the temperature on the ionic diffusion through the Ga-In composite was also assessed from $10^{\circ} \mathrm{C}$ to $40^{\circ} \mathrm{C}$ (Fig. S7d-f $\dagger$ ). The ionic diffusion was shown to increase with the rising temperature due to the possible ionic mobility increase in solution and within the PVA matrix, similar to previous reports. ${ }^{32}$

The electrochemical impedance spectroscopy (EIS) analysis was performed on the Ga-In composite (Fig. 4g). In the Nyquist 
plot, semicircles were observed in the higher frequency range in all salt solutions. ${ }^{48-50}$ In the solution containing $\mathrm{Li}^{+}$, a distinct large semicircle indicated the presence of extra ohmic losses due to impeded diffusion. In the lower frequency range, the GaIn composite also shows higher resistance for $\mathrm{Li}^{+}$as compared to $\mathrm{Na}^{+}$and $\mathrm{K}^{+}$. In the Bode plots of the Ga-In composite (Fig. 4h), the impedance increased steadily in the frequency range from $1.0 \times 10^{5}$ to $1.0 \mathrm{~Hz}$. Phase shifts were observed to peak at $250 \mathrm{~Hz}, 1200 \mathrm{~Hz}$, and $6000 \mathrm{~Hz}$ for $\mathrm{Li}^{+}, \mathrm{Na}^{+}$, and $\mathrm{K}^{+}$, respectively. The relatively high phase shift for the Ga-In composite in the presence of $\mathrm{Li}^{+}$at lower frequencies further suggests the impeded diffusion of the $\mathrm{Li}^{+}$ions through the matrix of the Ga-In composite as compared to $\mathrm{K}^{+}$and $\mathrm{Na}^{+} \cdot{ }^{48,49}$ These results confirmed our assumptions that the PVA/MA matrix would allow the diffusion of $\mathrm{K}^{+}$and $\mathrm{Na}^{+}$, as the posttransition metal fillers, and particularly Ga oxides and hydroxides, specifically hinder the diffusion of $\mathrm{Li}^{+}$through the material via specific interactions.

Separation - pure diffusion regime. The pure diffusion and separation performance of the composite for $\mathrm{Li}^{+}, \mathrm{Na}^{+}$and $\mathrm{K}^{+}$ binary and tertiary mixtures were then assessed in a diffusion cell as illustrated in Fig. 5a. The feed compartment contained the salt solutions as the permeate side of the cell was filled with a fixed volume of DI water. Diffusions of single $\mathrm{Li}^{+}$and $\mathrm{mix}_{\mathrm{Li}}^{+}$/ $\mathrm{Na}^{+}$across In and Ga-In composites are shown in Fig. 5b. Plain PVA/MA and Ga composites are not shown due to their poor stability after a relatively short exposure time to the solutions. In contrast, the In and Ga-In were found to remain stable in the solutions after prolonged exposure. After $2 \mathrm{~h}$ of diffusion, the In and Ga-In composites presented distinct diffusion behaviors in single and mixed salt solutions. The increase of conductivity in the permeate compartment was similar for the single $\mathrm{Li}^{+}$and $\mathrm{Li}^{+} / \mathrm{Na}^{+}$mixed feed solution for the In composite. The Ga-In composite presented a significant resistance to the $\mathrm{Li}^{+}$diffusion as shown by the important lag-time of $\mathrm{Li}^{+}$detection $(0.60 \pm 0.20$ min) as compared to $\mathrm{K}^{+}$and $\mathrm{Na}^{+}$ions $(0.05 \pm 0.01$ min lag-time) for a typical diffusion experiment (Fig. S8 $\dagger$ ). ${ }^{\mathbf{1 8 , 2 2}}$ The diffusion rate of $\mathrm{Li}^{+}$across the In composite was 4.3 times higher than that across the Ga-In composite indicating the effect of the dispersed $\mathrm{Ga}$ oxide and hydroxide species on the selective transport of $\mathrm{Li}^{+}$across the PVA/MA matrix. In addition, the increase of conductivity for the mixed $\mathrm{Li}^{+} / \mathrm{Na}^{+}$feed solution was 8 times higher as compared to the single $\mathrm{Li}^{+}$solution for the $\mathrm{Ga}-$ In composite indicating a selective transport mechanism. The selective transport across the Ga-In composite is further presented in Fig. 5c with diffusion rates of 11.7 times and 9.4 times higher for $\mathrm{K}^{+}$and $\mathrm{Na}^{+}$as compared to $\mathrm{Li}^{+}$, respectively, after $60 \mathrm{~min}$ of pure diffusion regime. The corresponding ionic fluxes are reported in Fig. S9a. $\uparrow$ The selective transport of $\mathrm{Li}^{+}, \mathrm{Na}^{+}$and $\mathrm{K}^{+}$ions was further confirmed with ICP-OES analysis for the binary salt mixtures $\mathrm{Li}^{+} / \mathrm{Na}^{+}, \mathrm{Li}^{+} / \mathrm{K}^{+}$and $\mathrm{K}^{+} / \mathrm{Na}^{+}$. The $\mathrm{Ga}-\mathrm{In}$ composite selectivity ratios were calculated as 3.8 for $\mathrm{Na}^{+} / \mathrm{Li}^{+}$, 7.1 for the $\mathrm{K}^{+} / \mathrm{Li}^{+}$, and 2.1 for $\mathrm{K}^{+} / \mathrm{Na}^{+}$which were amongst the highest selectivity ratios reported for mixed matrix separation materials. ${ }^{22,23}$ The corresponding conductivity measurements and calculated ionic fluxes of the binary salt mixtures are reported in Fig. S9b and $\mathrm{c}, \uparrow$ respectively.
The Ga-In composites were shown to exhibit selective separation properties rather than absorptive mechanisms as confirmed by the mass balance calculations between the feed and permeate compartment for a mixed $\mathrm{Li}^{+} / \mathrm{Na}^{+}$diffusion experiment (Fig. 5d), determined by ICP-OES and after $2 \mathrm{~h}$ of diffusion. The reversible nature of the separation mechanism and reusability of the materials was further assessed after a series of $1 \mathrm{~h}$ diffusion for mixed $\mathrm{Li}^{+} / \mathrm{Na}^{+}$feed solutions. The mass balances and selectivity ratios were determined from ICPOES measurements as presented in Fig. 5e. The $\mathrm{Li}^{+}$and $\mathrm{Na}^{+}$ mass balances between the feed and permeate compartments were found to be within the measurement errors with an average $\mathrm{Na}^{+} / \mathrm{Li}^{+}$selectivity ratios of $3.8 \pm 0.1$ confirming the reusable nature of the material.

The role of the nano-additives on the $\mathrm{Li}^{+}$selectivity mechanisms of the Ga-In composite was confirmed by studying the diffusion of mix $\mathrm{Li}^{+} / \mathrm{Na}^{+}$solutions across $\mathrm{Ga}$-In composite with increasing thicknesses from $20 \mu \mathrm{m}$ to $200 \mu \mathrm{m}$ as seen in Fig. $5 \mathrm{f}$. Increasing the thickness from 20 to 200 microns decreased the diffusivity by over 2 orders of magnitude (120 times) over 2 h. However, the $\mathrm{Li}^{+} / \mathrm{Na}^{+}$selectivity ratios were conserved after pure diffusion experiments (Fig. S9d $\dagger$ ), which indicated that the selectivity is arising from specific interactions with the nanoadditives and particularly Ga oxide and hydroxide species, as opposed to an increase in composite resistance due to longer path length through the thicker composite material. ${ }^{51,52}$ In addition, the Ga-In composites were formed with EGaIn additives of different average sizes (Fig. S2 $\dagger$ ). The SEM images of the surfaces of the Ga-In composites, containing different average sizes, are shown in Fig. S10† and presented different coverage of the PVA/MA matrix by the EGaIn additives. The Ga-In composites prepared with the $1.2 \pm 0.4$ and $0.7 \pm 0.3 \mu \mathrm{m}$ EGaIn additives (10 and 20 min sonication times, respectively) showed surface clusters of micron-sized particles. In contrast the Ga-In composites prepared with the $0.5 \pm 0.2 \mu \mathrm{m}$ (30 and $40 \mathrm{~min}$ sonication times) EGaIn additives showed a more uniform surface distribution. The roughness measurements of the composites are presented in Fig. S11 $\uparrow$ and followed the SEM observations, with a $R_{\mathrm{a}}$ decreasing as a function of the average sizes of the additives. The ionic diffusion performance of the Ga-In composites were evaluated and presented in Fig. S9e. $\dagger$ The Ga-In composites containing clusters of micron-sized EGaIn additives (10 and 20 min sonication time) showed higher non-selective ionic diffusivities that included high $\mathrm{Li}^{+}$ transport through the composites and into the permeate as determined by ICP-OES (Fig. S9f $\dagger$ ). These results further confirmed that the selectivity of the composites likely arises from interactions with the nano-additives present in the composites.

Finally, the continuous operation of the Ga-In composite was assessed for up to 5 days of separation experiment of a mixed tertiary $\mathrm{Li}^{+} / \mathrm{Na}^{+} / \mathrm{K}^{+}$feed solution in pure diffusion regime. The relative concentration changes in the feed and permeate compartments were monitored by ICP-OES as seen in Fig. $5 \mathrm{~g}$ and $\mathrm{h}$, respectively and by conductivity measurements (Fig. S9g and $\mathrm{h} \dagger$ ). The Ga-In composite was shown to continuously operate during the 5 day long experiment with a constant 
(a)

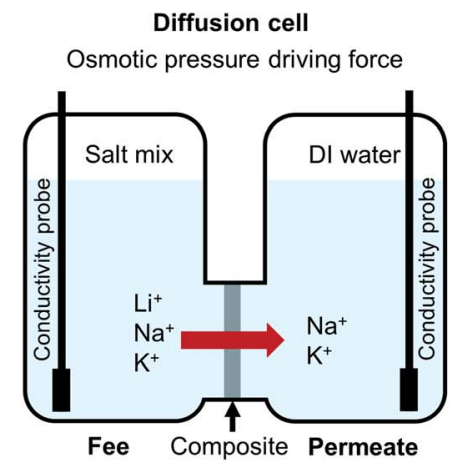

(d)

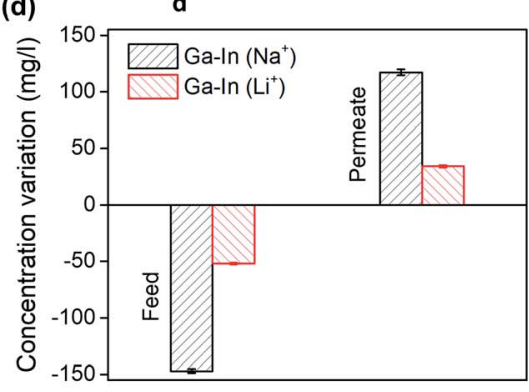

Single diffusion experiment

(g)

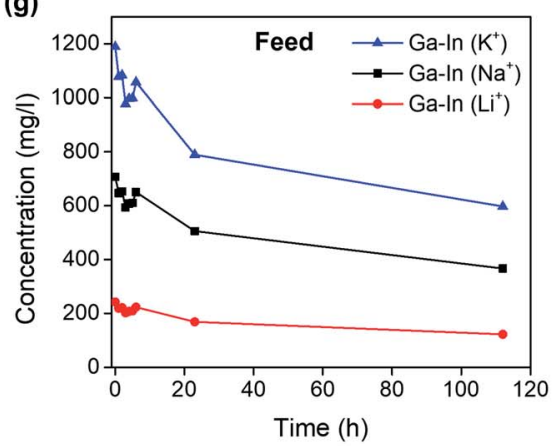

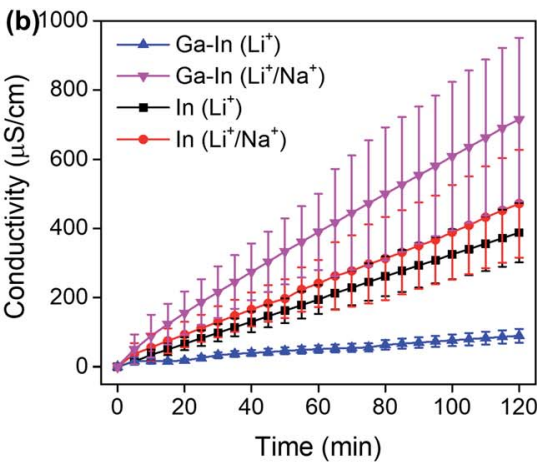

(e)

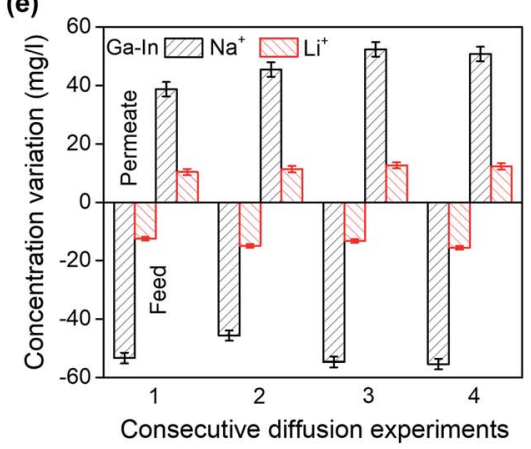

(h)

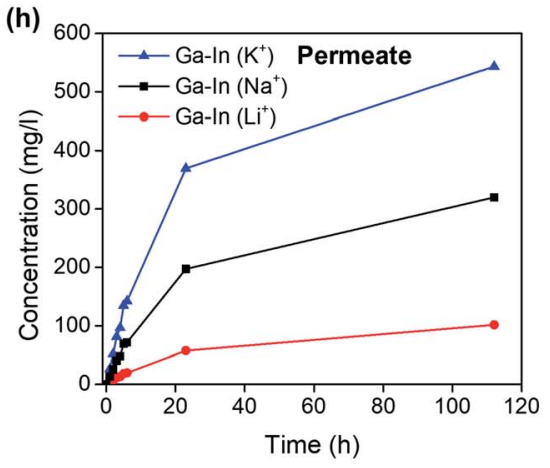

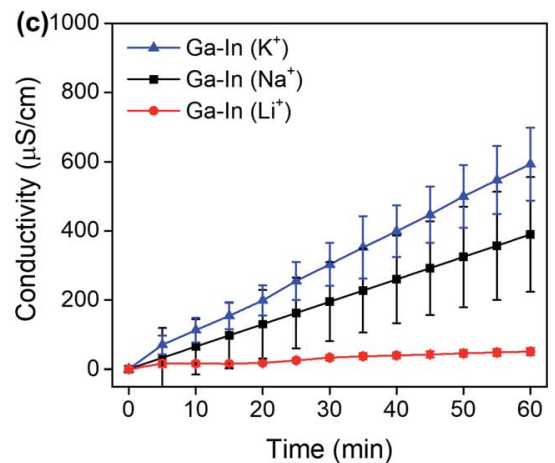

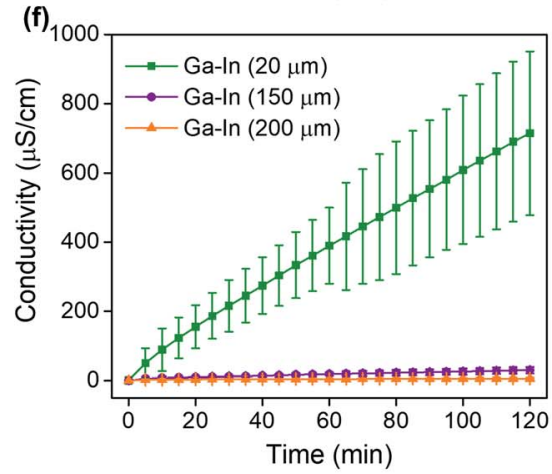

(i)

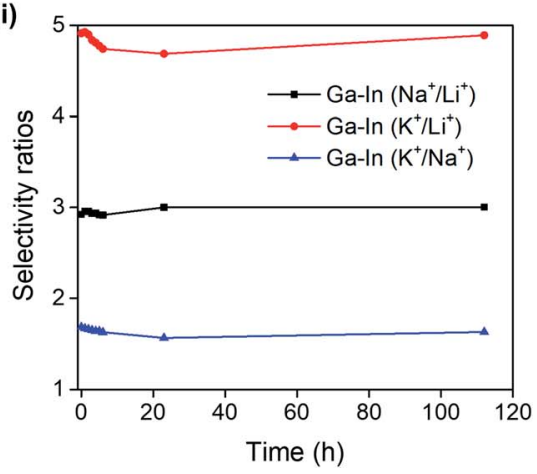

Fig. 5 (a) Schematic representation of the diffusion cell used for the selectivity experiments in pure diffusion regime. (b) lonic conductivity as a function of the diffusion time for the In and $\mathrm{Ga}-\mathrm{In}$ composites in $\mathrm{Li}^{+}$and mixed $\mathrm{Li}^{+} / \mathrm{Na}^{+}$electrolytes. (c) lonic conductivity as a function of the diffusion time for the $\mathrm{Ga}-\mathrm{In}$ composite in single $\mathrm{Li}^{+}, \mathrm{Na}^{+}$and $\mathrm{K}^{+}$electrolytes. (d) ICP-OES mass balance between the feed and permeate compartments of a mixed $\mathrm{Li}^{+} / \mathrm{Na}^{+}$separation experiment $(120 \mathrm{~min})$. (e) ICP-OES mass balance between the feed and permeate compartments after four successive $\mathrm{Li}^{+} / \mathrm{Na}^{+}$separation experiments (60 min each). (f) $\mathrm{Li}^{+} / \mathrm{Na}^{+}$separation experiments (120 min) for three different Ga-In composite thicknesses. (g) Relative concentration changes in the feed for a mixed $\mathrm{Li}^{+} / \mathrm{Na}^{+} / \mathrm{K}^{+}$separation experiment (110 h) as determined by ICP-OES, and ( $h$ ) in the permeate. (i) Selectivity ratios as a function of the diffusion time (110 h) as determined by ICP-OES.

separation factor as presented in Fig. 5i. Furthermore, the ionic diffusion rates were shown to decrease after the first $24 \mathrm{~h}$ of separation. For potential practical application, the feed and permeate would be refreshed during this timeframe for optimum separation efficiency.

Separation - electro-diffusion regime. The separation of $\mathrm{Li}^{+} /$ $\mathrm{Na}^{+}$feed solutions was performed in an electro-diffusion regime to study the effect of an electrical field on the ionic diffusion rate across the $\mathrm{Ga}$-In composite and its selective behavior. ${ }^{22}$ The electro-diffusion experiment set-up is illustrated in Fig. 6a and corresponded to configuration 1 , where the electrical field was applied between two electrodes placed in the feed and permeate compartment. Fluxes of $\mathrm{Li}^{+}$corresponding to configuration 1 are presented in Fig. $6 \mathrm{~b}$ and showed a linear increase of the diffusion rate as a function of the applied DC voltage as previously reported for electro-dialysis systems. ${ }^{22,53}$ In addition, the Ga-In composite was shown to be electrically conductive due to the In metallic nano-additives, which allowed for a direct polarization of the materials for further enhanced separation rates as illustrated in Fig. 6 a for configurations 2 and $1+2 .^{53,54}$ The electrical resistance of the Ga-In composite was measured at $0.2 \mathrm{k} \Omega$. Both configurations were shown to enhance the $\mathrm{Li}^{+}$ fluxes across the Ga-In composite by $32 \%$ and $51 \%$ for configuration 2 and $1+2$, respectively, as reported in the inset Fig. $6 \mathrm{~b}$. The direct polarization of the composite could provide an innovative solution to improve ionic diffusion rates that take 

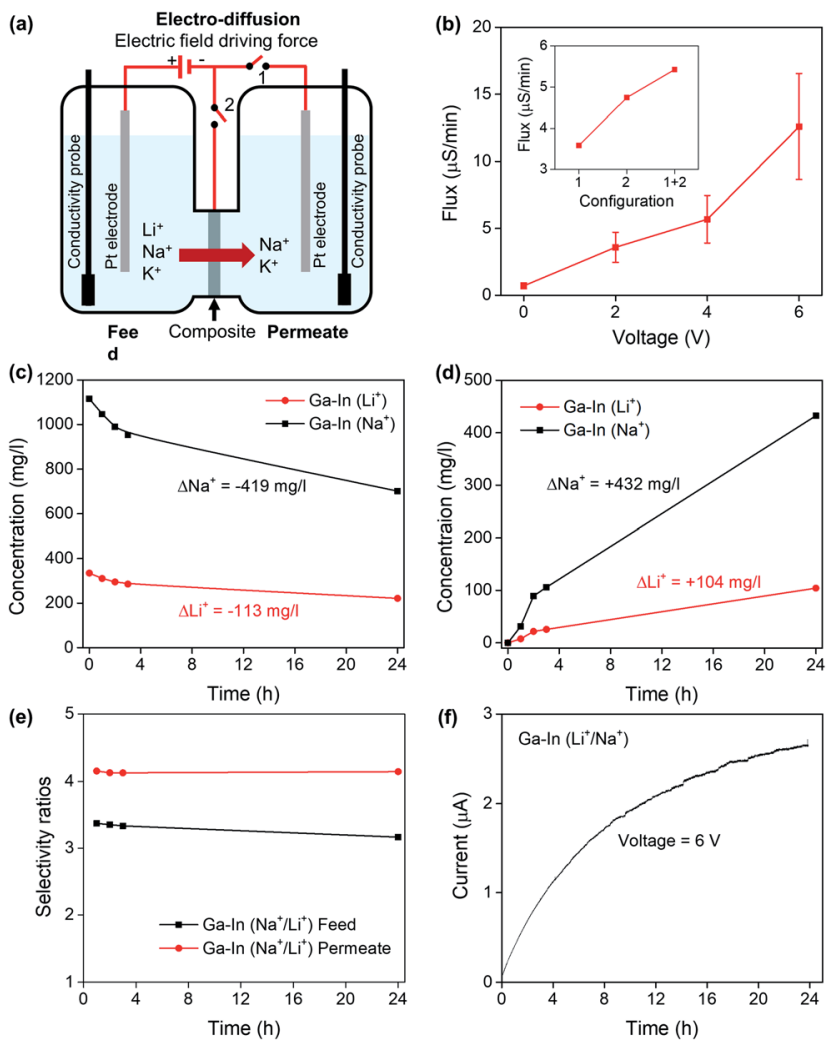

Fig. 6 (a) Schematic representation of the electro-diffusion experiments showing the three different configurations studied $(1,2$ and $1+$ 2). (b) Ionic fluxes as a function of the applied DC voltage for the Ga-In composite in $\mathrm{Li}^{+}$electrolyte and insert showing the ionic fluxes as a function of the electrode configuration for the $\mathrm{Ga}-\mathrm{In}$ composite in $\mathrm{Li}^{+}$electrolyte. (c) Relative change of ionic concentration in the feed compartment as a function of the electro-diffusion time for the $\mathrm{Ga}-\mathrm{In}$ composite in mixed $\mathrm{Li}^{+} / \mathrm{Na}^{+}$electrolyte at constant applied voltage (6 V), and (d) in the permeate compartment. (e) Calculated selectivity ratios as a function of the electro-diffusion time. (f) Change of intensity across the diffusion cell as a function of the electro-diffusion time.

full advantage of the electrical conductivity of the Ga-In composite. $^{54}$ Changes of conductivity in the permeate compartments are presented in Fig. S12a. $\dagger$

The separation of $\mathrm{Li}^{+} / \mathrm{Na}^{+}$feed solutions was performed with an applied DC voltage of $6 \mathrm{~V}$ across the feed and permeate compartments for $24 \mathrm{~h}$. The relative concentration changes across the compartments are presented in Fig. $6 \mathrm{c}$ and $\mathrm{d}$ and showed conservation of mass between the cathodic (feed) and anodic (permeate) compartments following a similar behavior as in the pure diffusion regime. Conductivity measurements in the anodic and cathodic compartments are reported in Fig. S12b and $c, \uparrow$ respectively. The selectivity ratios were also shown to be constant across the duration of the experiment (Fig. 6e) and similar to the pure diffusion experiments. The evolution of the intensity is reported in Fig. $6 \mathrm{f}$ and showed a steady rise following the increase of conductivity in the permeate compartment as seen in Fig. S12c. $\dagger$ The Ga-In composites were shown to perform in an electro-diffusion regime without loss of $\mathrm{Na}^{+} / \mathrm{Li}^{+}$selectivity while increasing the ionic flux by up to 17.8 times.

\section{Mechanism and durability assessment}

The inner morphology of the Ga-In composite, which can be related to the thickness of the material, was previously demonstrated to not affect the selectivity of the material but only the rate of diffusion (Fig. $5 \mathrm{f}$ and $\mathrm{S} 9 \mathrm{~d} \dagger$ ). $\mathrm{As}^{+}{ }^{+}, \mathrm{Na}^{+}$and $\mathrm{K}^{+}$ present the same valence and close ionic radii for physical separation, the selectivity of the Ga-In composite is related to the specific energy of interaction and stabilization between the ions and the charged domains across the composite. ${ }^{\mathbf{1 8 , 3 1}}$ The selectivity of the Ga-In composite was also demonstrated to be independent of the driving force, i.e. osmotic pressure in pure diffusion or electric field in electro-diffusion regime (Fig. 6e). In these regards, it is supposed that the Ga-In composite presents specific binding sites for $\mathrm{Li}^{+}$ions and non-specific obstacles to $\mathrm{Na}^{+}$and $\mathrm{K}^{+}$transport, respectively.

The overall charge of the composites and plain PVA/MA was determined by zeta potential measurements as reported in Fig. 7a. The strong negative charge of the plain PVA/MA can be explained by the negatively charged hydroxyl and carbonyl
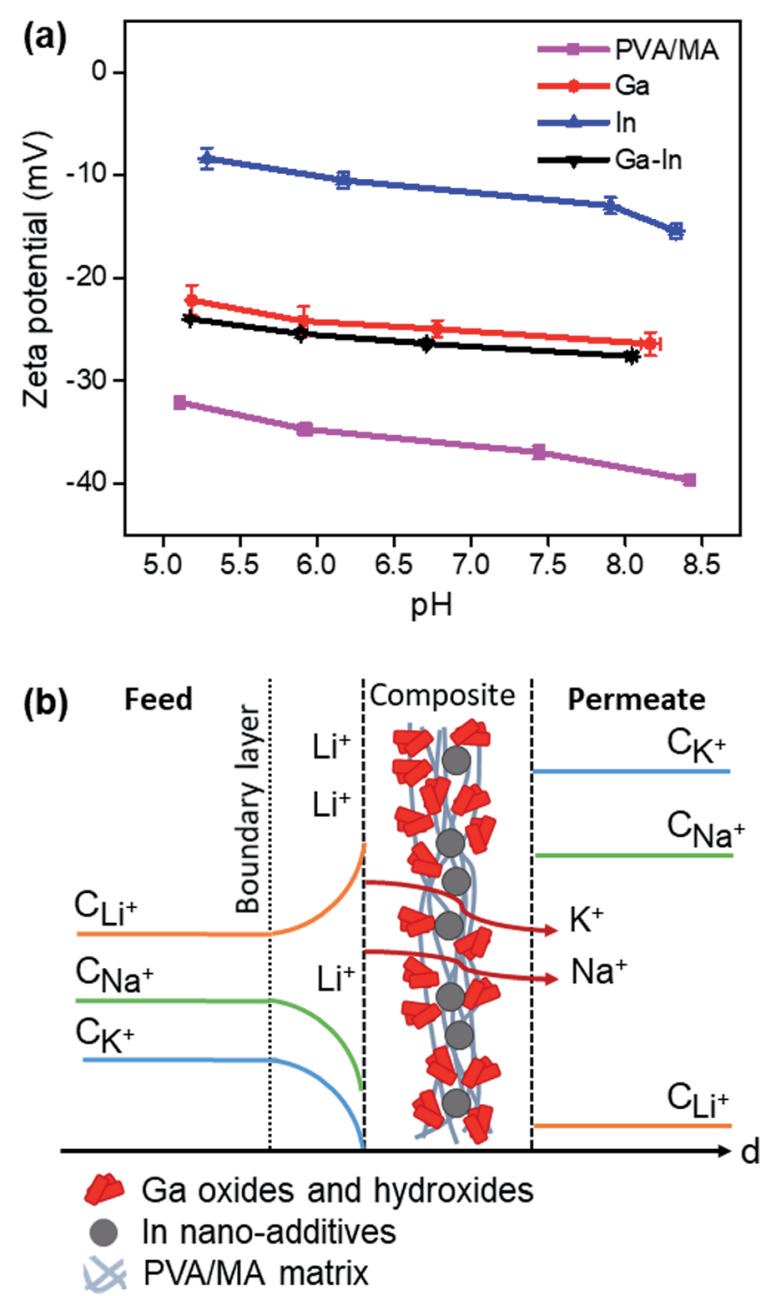

Fig. 7 (a) Zeta potential measurements of the composites as a function of the $\mathrm{pH}$. (b) Schematic representation of the proposed $\mathrm{Li}^{+}$ selectivity mechanism across the Ga-In composite. 
functional groups across the polymeric matrix, which should provide only limited selectivity to $\mathrm{Li}^{+}$based on the difference in charge density between $\mathrm{Li}^{+}, \mathrm{Na}^{+}$and $\mathrm{K}^{+}$ions. ${ }^{55,56}$ However, the charge surface of the PVA/MA matrix could not explain alone the impaired transport of $\mathrm{Li}^{+}$across the Ga-In composites. The zeta potential of the Ga-In composite was $25 \%$ higher than the plain PVA/MA and similar to that of plain Ga composite. This indicates that the $\mathrm{Li}^{+}$selectivity is likely due to strong and specific binding sites with the Ga oxide and hydroxide compounds present at the surface of the composite. The zeta potential measurements of the In composite revealed a less negatively charged surface than the other composites indicating strong coordination between the metallic In nano-additives and the functional groups of the PVA/MA matrix. A graphical representation of the proposed selectivity phenomena across the Ga-In composite is presented in Fig. 7b. The selectivity and separation performance of the Ga-In composites could be optimized with the formation of uniform nano-additives via controlled dealloying of the EGaIn particles, which could provide more enhanced active surface area and selective interstitial volume across the composites. ${ }^{57,58}$

Finally, the stability of the Ga-In composite was assessed after $110 \mathrm{~h}$ of diffusion in mixed $\mathrm{Li}^{+} / \mathrm{Na}^{+} / \mathrm{K}^{+}$solutions. The SEM/ EDS of the cross-section (Fig. S13a $\dagger$ ) showed a similar structure and elemental distribution as the pristine $\mathrm{Ga}$-In composite with round-shaped In nano-additives and Ga-rich domains matching the $\mathrm{O}$ elemental mapping, indicating a stable morphological structure. XRD, FTIR and Raman analyses, showed in Fig. S13b$\mathrm{d}, \dagger$ respectively, showed virtually identical spectra and patterns as compared to the pristine Ga-In composite, which indicated a chemically stable material.

\section{Conclusions}

Post-transition metal/polymer composites have been developed for the separation and sensing of alkali metal ions. The liquid EGaIn alloy was processed into nano-additives in an aqueous PVA/MA solution at room temperature. The dealloying of Ga from the EGaIn nano-additive into Ga oxide and hydroxide species provided specific binding sites for $\mathrm{Li}^{+}$, while the metallic In stabilized the polymeric matrix. The Ga-In composite exhibited exceptional $\mathrm{Li}^{+}$selectivity, good mechanical strength, and stability. In order to reduce the high cost associated with Ga and In, other post-transition metals such as tin or bismuth or their alloys could be further explored. The PVA matrix could also be replaced by naturally derived polymers such as cellulose or chitosan and cured with natural polyphenol species as mild cross-linking agents. While Ga and In metals have been independently studied for lithiation reactions, their alloys and metal/oxide combination present new opportunities for alkali metal separation and sensing.

\section{Author contributions}

S. M.: investigation, conceptualization, formal analysis, and writing - original draft. M. M., M. M., R. A.: resources and formal analysis. C. Z., S. C., F. C., W. X., Z. C., J. T., M. A. R.: resources. J. Z.: resources, formal analysis. A. R.: resources and conceptualization. G. L.: resources, conceptualization and, writing - review \& editing. K. K.-Z., J. T., F.-M. A.: conceptualization, writing - review \& editing and supervision.

\section{Conflicts of interest}

There are no conflicts to declare.

\section{Acknowledgements}

This work was supported by the Australian Research Council (ARC) Laureate Fellowship grant (FL180100053).

\section{Notes and references}

1 K. Kalantar-Zadeh, J. Tang, T. Daeneke, A. P. O'Mullane, L. A. Stewart, J. Liu, C. Majidi, R. S. Ruoff, P. S. Weiss and M. D. Dickey, ACS Nano, 2019, 13, 7388-7395.

2 K. Zuraiqi, A. Zavabeti, F.-M. Allioux, J. Tang, C. K. Nguyen, P. Tafazolymotie, M. Mayyas, A. V. Ramarao, M. Spencer, K. Shah, C. F. McConville, K. Kalantar-Zadeh, K. Chiang and T. Daeneke, Joule, 2020, 4, 2290-2321.

3 S. Ni, Q. Chen, J. Liu, S. Yang, T. Li, X. Yang and J. Zhao, J. Power Sources, 2019, 433, 126681.

4 M. Nagao, A. Hayashi and M. Tatsumisago, Electrochemistry, 2012, 80, 734-736.

5 A. Santhosha, L. Medenbach, J. R. Buchheim and P. Adelhelm, Batter. Supercaps, 2019, 2, 524-529.

6 Y. Wu, L. Huang, X. Huang, X. Guo, D. Liu, D. Zheng, X. Zhang, R. Ren, D. Qu and J. Chen, Energy Environ. Sci., 2017, 10, 1854-1861.

7 J. Sangster and A. Pelton, J. Phase Equilib., 1991, 12, 33-36.

8 W. Alexander, L. Calvert, R. Gamble and K. Schinzel, Can. J. Chem., 1976, 54, 1052-1060.

9 S. Merhebi, M. Mayyas, R. Abbasi, M. J. Christoe, J. Han, J. Tang, M. A. Rahim, J. Yang, T. T. Tan, D. Chu, J. Zhang, S. Li, C. H. Wang, K. Kalantar-Zadeh and F.-M. Allioux, ACS Appl. Mater. Interfaces, 2020, 12, 20119-20128.

10 J. Tang, S. Lambie, N. Meftahi, A. J. Christofferson, J. Yang, M. B. Ghasemian, J. Han, F.-M. Allioux, M. A. Rahim, M. Mayyas, T. Daeneke, C. F. McConville, K. G. Steenbergen, R. B. Kaner, S. P. Russo, N. Gaston and K. Kalantar-Zadeh, Nat. Nanotechnol., 2021, 16, 431-439.

11 K. Xu, B. Y. Zhang, M. Mohiuddin, N. Ha, X. Wen, C. Zhou, Y. Li, G. Ren, H. Zhang, A. Zavabeti and J. Z. Ou, Nano Today, 2021, 37, 101096.

12 A. Zavabeti, J. Z. Ou, B. J. Carey, N. Syed, R. Orrell-Trigg, E. L. H. Mayes, C. Xu, O. Kavehei, A. P. O'Mullane, R. B. Kaner, K. Kalantar-Zadeh and T. Daeneke, Science, 2017, 358, 332-335.

13 M. Zhang, X. Wang, Z. Huang and W. Rao, Biosensors, 2020, 10, 170.

14 B. Swain, Sep. Purif. Technol., 2017, 172, 388-403.

15 C. B. Tabelin, J. Dallas, S. Casanova, T. Pelech, G. Bournival, S. Saydam and I. Canbulat, Miner. Eng., 2021, 163, 106743. 
16 G. Martin, L. Rentsch, M. Höck and M. Bertau, Energy Storage Mater., 2017, 6, 171-179.

17 F. Meng, J. McNeice, S. S. Zadeh and A. Ghahreman, Miner. Process. Extr. Metall. Rev., 2021, 42, 123-141.

18 A. Razmjou, M. Asadnia, E. Hosseini, A. Habibnejad Korayem and V. Chen, Nat. Commun., 2019, 10, 5793.

19 E. Li, J. Kang, P. Ye, W. Zhang, F. Cheng and C. Yin, J. Mater. Chem. B, 2019, 7, 903-907.

20 J. Lu, H. Zhang, J. Hou, X. Li, X. Hu, Y. Hu, C. D. Easton, Q. Li, C. Sun, A. W. Thornton, M. R. Hill, X. Zhang, G. Jiang, J. Z. Liu, A. J. Hill, B. D. Freeman, L. Jiang and H. Wang, Nat. Mater., 2020, 19, 767-774.

21 Y. Sun, X. Guo, S. Hu and X. Xiang, J. Energy Chem., 2019, 34, $80-87$.

22 A. Razmjou, G. Eshaghi, Y. Orooji, E. Hosseini, A. H. Korayem, F. Mohagheghian, Y. Boroumand, A. Noorbakhsh, M. Asadnia and V. Chen, Water Res., 2019, 159, 313-323.

23 H. Zhang, J. Hou, Y. Hu, P. Wang, R. Ou, L. Jiang, J. Z. Liu, B. D. Freeman, A. J. Hill and H. Wang, Sci. Adv., 2018, 4, eaaq0066.

24 C. Zhang, F.-M. Allioux, M. A. Rahim, J. Han, J. Tang, M. B. Ghasemian, S.-Y. Tang, M. Mayyas, T. Daeneke, P. Le-Clech, R. B. Kaner, D. Esrafilzadeh and K. KalantarZadeh, Chem. Mater., 2020, 32, 4808-4819.

25 G. Chen, H. Wang, R. Guo, M. Duan, Y. Zhang and J. Liu, ACS Appl. Mater. Interfaces, 2020, 12, 6112-6118.

26 B. Yuan, C. Zhao, X. Sun and J. Liu, Adv. Funct. Mater., 2020, 30, 1910709.

27 M. Zhang, P. Zhang, C. Zhang, Y. Wang, H. Chang and W. Rao, Appl. Mater. Today, 2020, 19, 100612.

28 W. Hu, Y. Li, S.-Y. Tang, L. Li, Q. J. Niu and S. Yan, Adv. Mater. Interfaces, 2021, 2100038, DOI: 10.1002/ admi.202100038.

29 Y. Ohm, C. Pan, M. J. Ford, X. Huang, J. Liao and C. Majidi, Nat. Electron., 2021, 4, 185-192.

30 M. J. Ford, D. K. Patel, C. Pan, S. Bergbreiter and C. Majidi, Adv. Mater., 2020, 32, 2002929.

31 R. M. Putri, C. D. Sundari, O. Floweri, T. R. Mayangsari, A. L. Ivansyah, S. P. Santosa, I. M. Arcana and F. Iskandar, J. Non-Cryst. Solids, 2021, 556, 120549.

32 A. Kumar and S. S. Han, Int. J. Polym. Mater., 2017, 66, 159182.

33 B. Zhao, W. Ma, P. Zhang, Q. Zhang, J. Zhong and H. Matsuyama, Chem. Pap., 2020, 74, 3913-3923.

34 X. Cheng, W. Cai, X. Chen, Z. Shi and J. Li, RSC Adv., 2019, 9, 15457-15465.

35 J. Tang, R. Daiyan, M. B. Ghasemian, S. A. Idrus-Saidi, A. Zavabeti, T. Daeneke, J. Yang, P. Koshy, S. Cheong, R. D. Tilley, R. B. Kaner, R. Amal and K. Kalantar-Zadeh, Nat. Commun., 2019, 10, 4645.

36 F.-M. Allioux, S. Merhebi, J. Tang, S. A. Idrus-Saidi, R. Abbasi, M. G. Saborio, M. B. Ghasemian, J. Han, R. NamivandiZangeneh, A. P. O'Mullane, P. Koshy, R. Daiyan, R. Amal,
C. Boyer and K. Kalantar-Zadeh, Adv. Funct. Mater., 2020, 30, 1907879.

37 H. Lu, S.-Y. Tang, Z. Dong, D. Liu, Y. Zhang, C. Zhang, G. Yun, Q. Zhao, K. Kalantar-Zadeh, R. Qiao and W. Li, ACS Appl. Nano Mater., 2020, 3, 6905-6914.

38 R. Abbasi, M. Mayyas, M. B. Ghasemian, F. Centurion,

J. Yang, M. Saborio, F.-M. Allioux, J. Han, J. Tang, M. J. Christoe, K. M. Mohibul Kabir, K. Kalantar-Zadeh and M. A. Rahim, J. Mater. Chem. C, 2020, 8, 7805-7811.

39 C. E. Goodyer and A. L. Bunge, J. Membr. Sci., 2012, 409-410, 127-136.

40 Y. Fang and S. J. Duranceau, Membranes, 2013, 3, 196-225.

41 S. Cai, M. Mayyas, M. G. Saborio, M. B. Ghasemian, J. Tang, T. Daeneke, J. Han, A. A. Esmailpour, F.-M. Allioux and

K. Kalantar-Zadeh, J. Mater. Chem. C, 2020, 8, 16593-16602. 42 T. Liu, D. Chen, Y. Cao, F. Yang, J. Chen, J. Kang, R. Xu and M. Xiang, J. Membr. Sci., 2021, 618, 118679.

43 Z. Xie, M. Hoang, T. Duong, D. Ng, B. Dao and S. Gray, J. Membr. Sci., 2011, 383, 96-103.

44 F.-M. Allioux, S. Merhebi, J. Tang, C. Zhang, A. Merenda, S. Cai, M. B. Ghasemian, M. A. Rahim, M. Maghe, S. Lim, J. Zhang, L. Hyde, M. Mayyas, B. V. Cunning, R. S. Ruoff and K. Kalantar-Zadeh, Carbon, 2021, 171, 938-945.

45 W. Zhang, J. Z. Ou, S.-Y. Tang, V. Sivan, D. D. Yao, K. Latham, K. Khoshmanesh, A. Mitchell, A. P. O'Mullane and K. Kalantar-zadeh, Adv. Funct. Mater., 2014, 24, 3799-3807.

46 M. Mayyas, M. Mousavi, M. B. Ghasemian, R. Abbasi, H. Li, M. J. Christoe, J. Han, Y. Wang, C. Zhang, M. A. Rahim, J. Tang, J. Yang, D. Esrafilzadeh, R. Jalili, F.-M. Allioux, A. P. O'Mullane and K. Kalantar-Zadeh, ACS Nano, 2020, 14, 14070-14079.

47 S. Yang, F. Zhang, H. Ding, P. He and H. Zhou, Joule, 2018, 2, 1648-1651.

48 M. Mayyas and V. Sahajwalla, Chem. Eng. J., 2019, 358, 980991.

49 J. Lyu, M. Mayyas, O. Salim, H. Zhu, D. Chu and R. K. Joshi, Mater. Today Energy, 2019, 13, 277-284.

50 R.-L. Xie, Z.-M. Zong, F.-J. Liu, Y.-G. Wang, H.-L. Yan, Z.-H. Wei, M. Mayyas and X.-Y. Wei, RSC Adv., 2015, 5, 45718-45724.

$51 \mathrm{~J}$. Veerman, Energies, 2020, 13, 1946.

$52 \mathrm{H}$. Strathmann, Ion-exchange membrane separation processes, Elsevier, 2004.

53 F.-M. Allioux, L. He, F. She, P. D. Hodgson, L. Kong and L. F. Dumée, Sep. Purif. Technol., 2015, 147, 353-363.

54 F.-M. Allioux, S. Balme and L. F. Dumée, Mater. Horiz., 2018, 5, 1185-1193.

55 G. Liu, L. Zhang, S. Mao, S. Rohani, C. Ching and J. Lu, Sep. Purif. Technol., 2015, 152, 55-63.

56 M. Mohammad, M. Lisiecki, K. Liang, A. Razmjou and V. Chen, Appl. Mater. Today, 2020, 21, 100884.

57 A. Razmjou, J. Mansouri and V. Chen, J. Membr. Sci., 2011, 378, 73-84.

58 A. Razmjou, A. Resosudarmo, R. L. Holmes, H. Li, J. Mansouri and V. Chen, Desalination, 2012, 287, 271-280. 